\title{
Income Inequality and Education
}

\author{
Richard Breen, ${ }^{a}$ Inkwan Chung ${ }^{\mathrm{b}}$
}

a) University of Oxford; b) Yale University

Abstract: Many commentators have seen the growing gap in earnings and income between those with a college education and those without as a major cause of increasing inequality in the United States and elsewhere. In this article we investigate the extent to which increasing the educational attainment of the US population might ameliorate inequality. We use data from NLSY79 and carry out a three-level decomposition of total inequality into within-person, between-person and betweeneducation parts. We find that the between-education contribution to inequality is small, even when we consider only adjusted inequality that omits the within-person component. We carry out a number of simulations to gauge the likely impact on inequality of changes in the distribution of education and of a narrowing of the differences in average incomes between those with different levels of education. We find that any feasible educational policy is likely to have only a minor impact on income inequality.

Keywords: income inequality; income mobility; education; NLSY79; decomposition analysis; half the squared coefficient of variation

Citation: Breen, Richard, and Inkwan Chung. 2015. "Income Inequality and Education." Sociological Science 2: 454-477.

Received: April 3, 2015

Accepted: April 19, 2015

Published: August 26, 2015

Editor(s): Jesper Sørensen, Stephen Morgan

DOI: $10.15195 /$ v2.a22

Copyright: (C) 2015 The Author(s). This open-access article has been published under a Creative Commons Attribution License, which allows unrestricted use, distribution and reproduction, in any form, as long as the original author and source have been credited. (0)(1)
$\mathrm{T}^{\mathrm{N}}$ this article we examine the relationship between education and income in1 equality in the United States. We address two main questions. First how much of US income inequality can be attributed to education and, in particular, how important, as a cause of contemporary inequality, is the gap in income between college graduates and everyone else? Secondly suppose we could narrow the income gaps between people with different levels of educational attainment or change the distribution of education in the population: by how much could we expect inequality to decline? We focus on education because the growth in the college premium - that is, the difference in median earnings between college graduates and others-is frequently cited as an important source of America's growing inequality. From this it is a short step to the belief that increasing the educational attainment of the population would be an effective equalizing strategy. But would it? We know that median earnings differ greatly between, say, college graduates and high school graduates, but averages, whether means or medians, can sometimes be misleading and often capture only part of a complex picture.

To address our two questions we draw on insights from two strands of literature. One is work on income mobility, or volatility, mostly undertaken by economists, and the other is the decomposition approach to assessing the importance of categorical membership for income inequality. Bringing these together allows us to move beyond cross-sectional analyses of inequality to distinguish between two kinds of variation in income: variation in individuals' own incomes over time and variation between individuals in their average income. We follow many others in arguing that measures of inequality should be based on the latter and that conventional measures of inequality, based on income in a particular year, are biased because 
they contaminate income inequality with individual income volatility. Having established how we measure inequality, we then investigate the extent to which differences in education account for inequality. One can think of this in counterfactual terms: how much smaller would overall income inequality have been if average income differences between educational groups (for example, among those who went to college and those who did not) had been smaller, or if the distribution of education had been such that a greater proportion of people had a college degree? We show the results of simulation exercises aimed at addressing these questions. We find that education, although it is the strongest predictor of earnings and incomes that we know of, accounts for only a small part of income inequality. It is therefore not surprising that changing the educational distribution or narrowing the average differences in incomes between people with different levels of education is likely to have only modest effects on US income inequality.

\section{Education and Income Inequality in the Unites States}

Since the mid-1970s, economic inequality has risen in the United States: earnings, wages, individual incomes and household incomes have become increasingly unequal (Gottschalk 1997; Western, Bloome and Percheski 2008; McCall and Percheski 2010). According to the Congressional Budget Office (CBO 2011), between 1979 and 2007 inequality in disposable household income-that is, income after taxes had been deducted and government transfers, such as Social Security, Medicare, Medicaid, and food stamps had been included-increased by 25 per cent. The Gini index in 1979 was 0.397 ; in 2007 it stood at 0.489 .

Many commentators have seen the growing gap in earnings and incomes between those with a college education and those without as a major cause of increasing inequality (Goldin and Katz 2008). Autor (2014), for example, considers the growth in the wage premium associated with higher education and cognitive ability to be the most consequential factor in driving the growth of inequality among those households not in the top one percent ${ }^{1}$ The same argument is made repeatedly in the popular press. It has two corollaries: one is that a college education is necessary for avoiding the lowest reaches of the income distribution; the other is that more education for more people will be an effective way of curbing the rise in income inequality (see, for example, McCall and Kenworthy 2009 and Krugman 2015). Social scientists have often been skeptical of such claims. For example, Jencks et al (1979 189; see also Thurow 1975 64-5) drew attention to the fact that "the equalization of men's educational attainment during the twentieth century has not been accompanied by much, if any, equalization of earnings" Jencks (1972 224) earlier argued that "equalizing everyone's educational attainment would have virtually no effect on income inequality" But they were writing in very different social and economic circumstances; perhaps things are different today. ${ }^{2}$

There have been many attempts to explain the growth in inequality in the United States and elsewhere and many methods of analysis have been used, including decompositions (Mookherjee and Shorrocks 1982; DiNardo, Fortin and Lemieux 1996). Typically, given a comparison of income inequality at time $t+1$ with inequality at $t$, decomposition, or shift-share analyses involve the comparison of the 
distribution of income at $t+1$ with a counterfactual distribution, also relating to $t+1$, but which has been generated by allowing some determinants of income to change between $t$ and $t+1$ while keeping others fixed as they were at $t$. Breen and Salazar (2011) is one of several sociological analyses that use this approach. They ask how much of the change in income inequality in the United States between the late 1970s and early 2000s can be attributed to changing patterns of educational assortative mating. They try to answer this question by generating a hypothetical distribution of income for the 2000s, keeping the pattern of educational assortative mating as it was in the 1970s, and comparing this distribution with the actual 2000s distribution.

But the decomposition approach can also be applied to shed light on the determinants of income inequality at a given point in time (for example, Cowell and Jenkins 1995, among many others). Through the use of decomposable measures of inequality it becomes possible to answer the question of how much of total inequality lies among people or households within defined groups (such as educational or age groups) and how much lies between the groups. The greater the degree to which inequality lies between groups the stronger is group membership as a determinant of inequality. We use decomposition analysis for that purpose in this article. This means that our focus is not on trends in inequality or on what has driven them; rather, we want to investigate the extent to which contemporary income inequality can be accounted for by differences in the education that people possess.

One difficulty that confronts decompositions and other analyses of income inequality is that the measure of inequality itself is likely to be biased. Inequality at a given point in time, and comparisons of overall inequality across time points, will not capture inequality, or changes in inequality, in longrun incomes. Although the distribution of income among families may be unequal in any given year this does not mean it is necessarily unequal over the long term. Many families move up and down the income distribution (Gottschalk and Moffitt 1994; McMurer and Sawhill 1996; Gottschalk 1997). Van Kerm (2004), in a comparison of Belgium, Germany and the United States showed that most of this mobility involved a change in rank order in the distribution. Inequality will not be persistent if families' positions in the income distribution are not stable (Auten, Gee and Turner 2013) and for this reason inequality in a given year-or even rising inequality over several years-may be of less concern if it is offset by income mobility (Krugman 1992; Carroll 2010; Bradbury and Katz 2011). This implies that we should consider inequality and volatility or individual mobility, simultaneously, but for this we require data on the incomes of specific households followed over an extended period of time rather than the cross-sectional information usually used in studies of inequality.

Although sociologists have long been interested in intergenerational mobility, relatively few have focused on intragenerational mobility (Ganzeboom, Treiman and Ultee 1991; Hout 2004; Kim and Sakamoto 2008). And those life course researchers who have studied intergenerational mobility have mostly focused on career mobility (Hallinan 1988; Rosenfeld 1992). The field of intra-generational income mobility has thus largely been left to economists, and they have found substantial mobility over both the short and long term (Carroll 2010). Although there are differences in detailed figures depending on data and methods, studies 
have shown that approximately half of households in the lowest quintile of the US income distribution at any point will move to a higher quintile within a decade. Similarly, between 40 and 50 percent of the highest quintile will move to a lower quintile within a decade (Sawhill and Condon 1992; Bradbury and Katz 2002). There is also substantial mobility in the middle quintiles. Overall, between the 1960s and the 2000s, more than half of individuals and families moved to a different quintile of the distribution within a decade (McMurrer and Sawhill 1996; Bradbury and Katz 2002). On the other hand, rates of mobility in the United States do not seem to be unusually high when compared with western European countries (McMurrer and Sawhill 1996; Gottschalk and Smeeding 1997; Gangl 2005; Levine 2012), suggesting that higher cross-sectional inequality in the United States is not offset by greater intragenerational mobility.

Whether intragenerational mobility offsets inequality is not our focus; instead we are concerned with how mobility, or volatility in incomes affects estimates of inequality. As we explain below, income inequality measured using observed incomes in one year will most likely be upwardly biased. Before we can address the question of the importance of education for income inequality we will need to find a way of removing that bias from our estimates of inequality.

In this article we focus on income rather than earnings because income is a stronger determinant of individual standards of living. Earnings may certainly be thought to be a more direct consequence of education than income, but many of the things that make up income, aside from individual earnings are also, to some degree, consequences of education. These include whether and whom one marries, whether one has children and how many, whether one is forced to live with others or may live independently, and so on. We use income rather than earnings because we want to say something about the kind of life chances that people with different levels of education enjoy. But, as we report at the end of our article, we replicated our findings using earnings.

The article proceeds as follows. In the next section we discuss the data that we use, then we explain how we deal with the confounding of within-person volatility and between-person inequality. We present some estimates of income inequality purged of this confounding and show that it is, as expected, lower than the unadjusted estimates. Then we move to the central theme of the article and investigate the degree to which inequality in incomes is shaped by differences in educational attainment. We employ a three-level decomposition of total inequality into within-person, between-person and between-education parts. We find that the between-education contribution to inequality is small, even when we consider only adjusted inequality that omits the within-person component. We carry out a number of simulations to gauge the possible impact on inequality of changes in the distribution of education and narrowing of the differences in average incomes between those with different levels of education. We conclude with a discussion of the implications of our findings for whether and to what extent education might be the key to reducing inequality. 


\section{Data}

We use data from the National Longitudinal Survey of Youth 1979 (NLSY79), an ongoing panel whose first wave in 1979 interviewed a nationally representative sample of 12686 respondents aged 14 to 22 . The original survey consisted of a crosssectional sample of 6111 people and three supplemental samples: 3652 civilian Hispanic or Latino and black respondents; 1643 economically disadvantaged nonblack and non-Hispanic persons; and a military sample of 1280 respondents. Only data from the original sample of 6111 and the civilian Hispanic or Latino and black samples are used in this article because the other two supplemental samples were not included in all subsequent waves. Data were collected annually up to 1994, after which they were collected every second year. We use data up to and including $2010 .^{3}$

We analyze inequality in the incomes of the households in which NLSY79 respondents lived. Income data are collected retrospectively: data in the year $t$ survey refers to annual income in year $t-1$. We restrict our income information to NLSY79 respondents aged over 25 . We chose this cutoff because we want to focus on NLSY79 respondents' household incomes ${ }^{4}$ after they completed their education but we also want to avoid the selection bias that would arise if we used the incomes of respondents who left school early. For example, NLSY79 income data from the early 1980s will overwhelmingly be drawn from respondents with relatively few years of schooling. However, starting our income observations of each respondent at age 26 introduces a potential problem. Because of the age range of the NLSY79 sample, the year in which we start observing income (when respondents turn 26) potentially varies between 1983 and 1990, with older respondents being over-represented among the earlier observations. To overcome this, we separated the NLSY79 sample into two birth cohorts, 1957-9 and 1962-4, and we used information on their incomes starting in 1985 and 1991, respectively, when they were aged between 26 and 28 (between 27 and 29 for the younger cohort), depending on their exact year of birth. Throughout we analyze the two cohorts separately, though results for both are very similar. We examine incomes over 21 years, from 1985 to 2005 for the 1957-9 cohort and over 19 years, from 1991 to 2009 for the 1962-4 cohort.

After 1994 NLSY79 respondents were interviewed every second year; to avoid over-representation of pre-1994 observations we use surveys from every other year from 1986 to 2010. Our measure of income is NLSY79's own total net family income variable that includes for all household members related to the respondent by blood or marriage, income from a diversity of sources, such as wages, salaries, and net business income as well as government transfers through unemployment compensation, food stamps, Aid to Families with Dependent Children (AFDC), and other welfare payments. ${ }^{5}$ Top-coded incomes were excluded and all incomes are expressed in 2009 dollars Incomes are equivalized by dividing by the square root of household size. Missing incomes were imputed as an average of adjacent incomes (so, for example, missing income in 1995 was imputed as the average of 1993 and 1997 incomes) provided those incomes were not themselves missing. ${ }^{6}$ For the older (born 1957-9) cohort we have data on 2999 individual NLSY79 respondents 
and 23712 income observations; for the later (born 1962-4) cohort we have 3580 individuals and 26445 income observations.

\section{Measurement error}

Estimates of inequality based on incomes from a single year will be upwardly biased. We write the observed income in year $t$ for the $i^{t h}$ household, $y_{i t}$, as

$$
\begin{aligned}
y_{i t} & =x_{i}+d_{i t}+e_{i t} \\
& =x_{i t}+u_{i t} .
\end{aligned}
$$

Here $x$ is permanent or lifetime or long-run income, $d$ represents annual departures from permanent income as a result of volatility of incomes or income mobility (this is sometimes called the transitory component of income), and $e$ is measurement error in incomes ${ }^{7}$ We cannot distinguish measurement error from volatility so we combine $d$ and $e$ into a single error term, $u$. We sometimes refer to this as volatility and at other times as error, though it is a combination of both. Assuming that we really care about inequality in long-run incomes, rather than in an individual year's incomes, we can express the bias that arises from the presence of $u$ as follows. The variance of measured income in a single year, which we denote $\sigma_{Y}^{2}$, is given by

$$
\sigma_{Y}^{2}=\sigma_{X}^{2}+\sigma_{u}^{2}+2 \operatorname{cov}(X, u) .
$$

Under the assumption that the error, $u$, is independent of permanent income the covariance term is zero, and so the variance of the annual observed income, $y$, will be greater than the true variance of permanent income by a quantity that depends on the variance of $u$.

To overcome this problem of the inflation of the variance of observed incomes, we consider inequality between NLSY79 respondents over several years but rather than averaging their incomes over these years, as is often done to remove volatility, we decompose the total inequality in incomes over respondents and years into two parts: within-person and between-person inequality (the same approach was used for this purpose by Buchinsky and Hunt 1999). Within-person inequality captures the average variation across years in the incomes of individual respondents; between-person inequality captures the variation between individuals in their average income.

To make this decomposition we use a standard measure of inequality, half the squared coefficient of variation, henceforth $h$. This is a member of the class of generalized entropy measures, which has many desirable properties, including decomposability (see Bourguignon 1979 and Shorrocks 1980 for discussions of desirable properties of inequality measures).

The formula for $h$ is:

$$
h=\frac{1}{2}\left(\frac{\sigma}{\mu}\right)^{2}
$$

Here, $\mu$ is the average income over all observations of income and $\sigma$ is their standard deviation. In our case an observation means an NLSY79 respondent's income in a particular year. 
The measure decomposes as

$$
h=h_{w}+h_{b}=\left[\frac{1}{2 \mu^{2}} \sum_{i} p_{i} \sigma_{i}^{2}\right]+\left[\frac{1}{2 \mu^{2}} \sum_{i} p_{i}\left(\mu_{i}-\mu\right)\right] .
$$

We use $i$ to denote individual NLSY79 respondents, whose incomes we record over years, $t$. The total number of observations of annual incomes contributed by the $i^{\text {th }}$ person, as a share of the total of number of year-by-person income observations is $p_{i}$. The mean and standard deviation of each person's incomes (measured over years, $t)$ are $\mu_{i}$ and $\sigma_{i}$. The first term on the right of Equation (4) is the withinperson inequality and the second term is the between-person inequality. Because the latter captures inequality in long-run incomes it is a better measure of inequality in permanent incomes than would be $h$ (or any other inequality measure) computed using incomes for a single year.

\section{Income mobility}

We begin our analysis by presenting descriptive data on income mobility in the form of cross-tabulations of income quintiles at different ages. Table 1 shows three such mobility tables: (1) in panel A income quintile at 26 (29 for the younger cohort) years old, shown in the rows, is cross-tabulated with income quintile at 46 (47 for the younger cohort), shown in the columns; (2) in panel B income at 26 to 28 (27 to 29 for the younger cohort) is cross-tabulated with income at 32 to 34 (33 to 35 for the younger cohort); and (3) in panel C income at 40 to 42 (39 to 41 for the younger cohort) is cross-tabulated with income at 46 to 48 ( 45 to 47 for the younger cohort). Thus, panel A shows total net mobility for the entire period of the career over which we follow the NLSY79 respondents, while panels B and C show shorter term mobility at the start and end of this period.

All the tables show considerable movement between income quintiles, with a consistent pattern of greater persistence in the top and bottom quintiles. Comparing the two cohorts in panel A we see a little less mobility among the younger cohort: 62 percent of the 1962-4 cohort were in a different quintile at age 46 than at age 27, compared with 65 percent of the 1957-9 cohort. We observe less mobility in the shorter periods, shown in panels B and C, and greater stability at an older age Of the 1957-9 cohort 57 percent were in a quintile at age 34 different to the one they occupied at age 27, whereas at age 47,49 percent were in a quintile different to the one they occupied six years earlier. The comparable figures for the 1962-4 cohort are 54 percent and 50 percent. These results differ little from those found in earlier research, which also showed considerable economic mobility in the United States (McMurrer and Sawhill 1996; Bradbury and Katz 2002; Carroll 2010), though the decline in mobility with age is less pronounced in our data (Hubbard, Nunns and Randolph 1992).

\section{Income inequality}

We computed inequality in household incomes using $h$ for every second year from 1985 to 2005 for the 1957-9 cohort and from 1991 to 2009 for the 1962-4 cohort: 
Table 1: Transition Matrices, Income Quintiles

\begin{tabular}{|c|c|c|c|c|c|c|c|c|c|c|c|}
\hline \multirow[t]{2}{*}{ Panel A } & \multicolumn{6}{|c|}{ 1957-9 cohort, ages 26 to 46 (28-48) } & \multicolumn{5}{|c|}{ 1962-4 cohort, ages 27 to 45 (29-47) } \\
\hline & Highest & Second & Third & Fourth & Lowest & & Highest & Second & Third & Fourth & Lowest \\
\hline Highest & 44.7 & 25.2 & 16.6 & 8.6 & 4.8 & Highest & 48.5 & 24.4 & 13.0 & 10.5 & 3.6 \\
\hline Second & 27.9 & 26.6 & 24.4 & 15.1 & 6.1 & Second & 22.2 & 32.1 & 24.6 & 11.8 & 9.4 \\
\hline Third & 14.7 & 23.6 & 23.6 & 24.8 & 13.4 & Third & 16.1 & 21.4 & 28.3 & 22.5 & 11.7 \\
\hline Fourth & 8.3 & 17.9 & 20.1 & 30.4 & 23.3 & Fourth & 10.9 & 14.1 & 23.1 & 29.8 & 22.1 \\
\hline Lowest & 4.8 & 6.7 & 15.3 & 20.8 & 52.7 & Lowest & 2.5 & 8.4 & 10.9 & 25.3 & 53.0 \\
\hline \multirow[t]{2}{*}{ Panel B } & \multicolumn{6}{|c|}{$1957-9$ cohort, ages 26 to $32(28-34)$} & \multicolumn{5}{|c|}{ 1962-4 cohort, ages 27 to 33 (29-35) } \\
\hline & Highest & Second & Third & Fourth & Lowest & & Highest & Second & Third & Fourth & Lowest \\
\hline Highest & 53.3 & 24.1 & 13.3 & 7.5 & 1.7 & Highest & 55.0 & 27.5 & 9.2 & 4.4 & 3.9 \\
\hline Second & 24.1 & 38.8 & 23.3 & 9.5 & 4.3 & Second & 24.4 & 34.7 & 25.3 & 10.3 & 5.3 \\
\hline Third & 13.1 & 23.3 & 29.5 & 24.8 & 9.3 & Third & 9.9 & 22.8 & 36.2 & 21.7 & 9.5 \\
\hline Fourth & 6.1 & 9.5 & 27.7 & 32.9 & 23.9 & Fourth & 8.2 & 10.6 & 20.1 & 38.0 & 22.4 \\
\hline Lowest & 3.5 & 4.3 & 8.1 & 24.6 & 59.5 & Lov & 2.1 & 4.8 & 8.5 & 25.6 & 59.0 \\
\hline \multirow[t]{2}{*}{ Panel C } & \multicolumn{6}{|c|}{ 1957-9 cohort, ages 40 to $46(42-48)$} & \multicolumn{5}{|c|}{$1962-4$ cohort, ages 39 to $45(41-47)$} \\
\hline & Highest & Second & Third & Fourth & Lowest & & Highest & Second & Third & Fourth & Lowest \\
\hline Highest & 61.2 & 23.2 & 8.5 & 4.8 & 2.3 & Highest & 65.8 & 18.6 & 7.6 & 4.2 & 3.9 \\
\hline Second & 21.2 & 39.0 & 24.9 & 11.0 & 4.0 & Second & 20.1 & 44.5 & 21.8 & 10.8 & 2.9 \\
\hline Third & 7.5 & 22.5 & 41.0 & 22.8 & 6.1 & Third & 8.3 & 24.0 & 39.1 & 20.1 & 8.6 \\
\hline Fourth & 6.4 & 10.2 & 20.7 & 40.6 & 22.1 & Fourth & 2.7 & 10.5 & 25.4 & 39.4 & 22.0 \\
\hline Lowest & 3.7 & 2.8 & 7.1 & 21.2 & 65.3 & Lowest & 3.2 & 2.4 & 6.1 & 25.7 & 62.6 \\
\hline
\end{tabular}

we refer to this as annual inequality. We also computed total inequality (that is, including both inequality within persons over time and inequality between persons) over the whole observation period (1985-2005 and 1991-2009) and for three periods of six years: 1985-91, 1993-9 and 1999-2005 for the older cohort and 1991-97, 19972003 and 2003-09 for the younger cohort. In Figures 1 and 2 black points are used to show these estimates (the open points are discussed later). The line connecting the annual estimates, derived in the conventional way, shows an increasing trend in both cohorts, rising from an $h$ of 0.22 to 0.29 for the 1957-9 cohort and from 0.22 to 0.30 for the younger cohort. The $h$ values for periods, shown as triangles, are slightly higher for the 1962-4 cohort and the overall $h$, shown as a circle, is 0.28 for this cohort, compared with 0.25 for the 1957-9 cohort (in Figure 2 the triangle for the middle period and the circle for overall inequality coincide)

\section{Income inequality decompositions}

In Table 2 we report the decompositions of inequality over the entire observation period and in the three shorter periods described above. In each case, within-person inequality reflects both variation in individual respondents' annual household incomes over the particular time period and error in the measurement of income. 


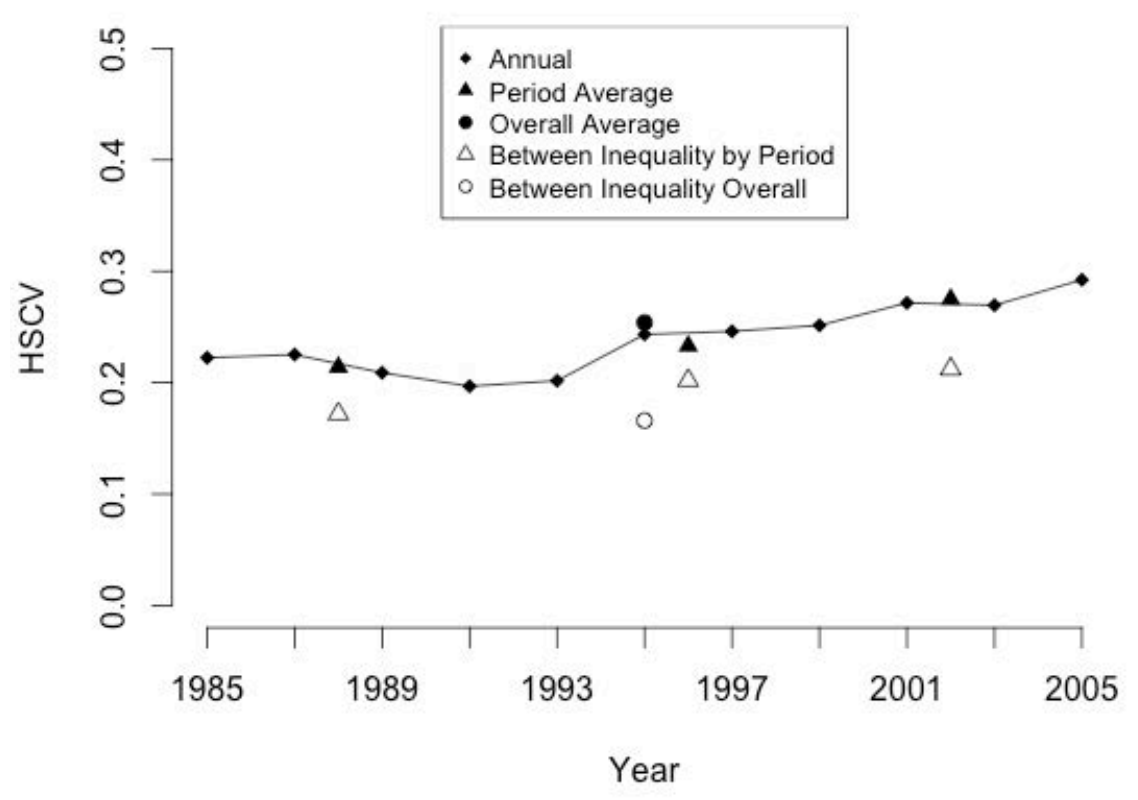

Figure 1: Inequality Measures, 1957-59 Cohort

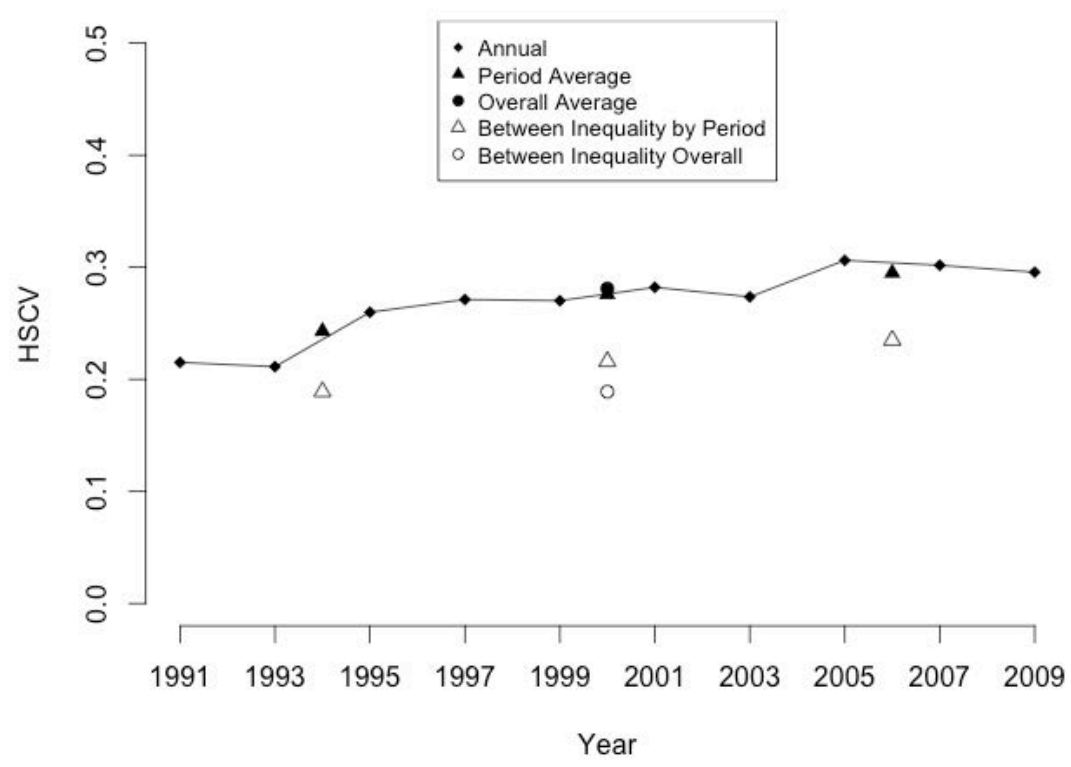

Figure 2: Inequality Measures, 1962-64 Cohort 
Table 2: Half Squared Coefficient of Variation Decomposition for Birth Cohorts and Time Periods

\begin{tabular}{lcccc}
\hline Period & Total & Between & Within & Between/Total \\
\hline 1957-9 cohort & & & & \\
1985-2005 & 0.254 & 0.166 & 0.088 & 0.654 \\
1985-1991 & 0.214 & 0.172 & 0.042 & 0.804 \\
1993-1999 & 0.233 & 0.202 & 0.031 & 0.867 \\
1999-2005 & 0.275 & 0.223 & 0.051 & 0.811 \\
1962-4 cohort & & & & \\
1991-2009 & 0.281 & 0.189 & 0.092 & 0.673 \\
1991-1997 & 0.232 & 0.197 & 0.035 & 0.849 \\
$1997-2003$ & 0.276 & 0.232 & 0.044 & 0.841 \\
2003-2009 & 0.295 & 0.240 & 0.055 & 0.814 \\
\hline
\end{tabular}

The within-person component is larger over the whole period (19 or 21 years depending on the cohort) than in any of the shorter periods and is strikingly larger as a proportion of total inequality, making the difference between total inequality and between-person inequality greatest over the entire period (their ratio is shown in the final column of Table 2). This is what we would have expected: the longer the period, the greater the variation within individuals' annual incomes. The betweenperson components of inequality are shown in Figures 1 and 2 as open triangles (for each shorter period) and an open circle for the whole period. Comparing these with the black triangles and circles we see the reduction in estimated inequality brought about by removing within-person variation. As Table 2 shows, inequality is reduced to about two thirds of its uncorrected value for the entire period. For the shorter periods, the reduction is generally to around 80 percent of the uncorrected value. Bound and Krueger (1991) found, similarly, that the true variance of year-to-year changes in annual earnings in the United States was about two thirds of the variance in reported changes.

\section{How much does education matter?}

Having shown how we can use the decomposition method to correct our estimates of income inequality to deal with individual income volatility, we now decompose income into three levels: between education groups, between persons within education groups, and within persons, over time. Although much of the debate on the role of education in inequality focuses on the college premium, we use four categories of education, distinguishing "less than high school" "high school" (this includes those with a GED), "some college" and "college" "College" means acquiring a four-year college degree or a higher qualification, while "some college" means a two-year college qualification or some years spent in college without acquiring a degree. Table 3 shows the distribution of income observations and individuals across these four educational categories. About one sixth of respondents have a four-year college degree or higher and about 40 percent have some experience 
Table 3: Numbers of Cases and Income Observations by Educational Category

\begin{tabular}{lrrrr}
\hline & \multicolumn{2}{c}{$1957-9$ cohort } & \multicolumn{2}{c}{$1962-4$ cohort } \\
& Cases & Observations & Cases & Observations \\
\hline < High School & 549 & 4,062 & 521 & 3,561 \\
High School & 1,234 & 10,040 & 1,703 & 12,652 \\
Some College & 713 & 5,657 & 772 & 5,743 \\
College & 503 & 3,953 & 584 & 4,489 \\
\hline
\end{tabular}

of college; 18 percent of the older cohort and 14 percent of the younger did not complete high school.

The three-level decomposition of $h$ can be written:

$$
\begin{aligned}
& h=h_{b e}+h_{b p}+h_{w}= \\
& {\left[\frac{1}{2 \mu^{2}} \sum_{j} p_{j}\left(\mu_{j}-\mu\right)^{2}\right]+\left[\frac{1}{2 \mu^{2}} \sum_{j} p_{j} \sum_{i \mid j} p_{i \mid j}\left(\mu_{i \mid j}-\mu_{j}\right)^{2}\right]+\left[\frac{1}{2 \mu^{2}} \sum_{j} p_{j} \sum_{i \mid j} p_{i \mid j} \sigma_{i \mid j}^{2}\right] .}
\end{aligned}
$$

Here $h_{b e}$ is between-education inequality, $h_{b p}$ is inequality between persons within educational categories, and $h_{w}$ is inequality within persons over years. In the formula, $i$ indexes persons and $j$ educational categories. We use $\mu_{i \mid j}$ to indicate the mean of the income of the $i^{\text {th }}$ person in the $j^{\text {th }}$ educational category, and $\sigma_{i \mid j}$ denotes the variance of income within the $i^{\text {th }}$ person in the $j^{\text {th }}$ educational category.

In panel A of Table 4 we show the mean incomes in each educational category and in panel B we report the medians. ${ }^{8}$ Mean and median incomes for all education groups increase as they grow older but the gap between college and the other categories also widens. Over the entire period, the average gap in medians between those who complete college and those who complete no more than high school is $\$ 25,000$ among those born 1957-9 and almost \$31,000 among those born 1962-4 (recall that the older cohort's incomes come from 1985 through 2005 while those for the younger cohort come from 1991 through 2009).

Panel C shows the standard deviations of income. These increase as the mean increases and so the standard deviation is larger the higher the education and the later in the career that income is observed But the most important information is found in panel D of Table 4, which shows that the single largest component of $h$ is, in all cases, that which lies between persons within categories of education. Next largest is the component that captures within-person volatility and error. The between-education component of inequality is rather small, accounting for less than one fifth of total inequality and between 20 and 25 percent of inequality adjusted for individual volatility (that is, inequality excluding the within-person component). There are very few differences in this percentage between either periods or cohorts. Furthermore, between-education inequality is quite stable over the career, though slightly greater in the younger cohort. The remainder of adjusted inequality is inequality among persons with the same education: this is at least three times as large as inequality between educational categories. 
Table 4: Means and Standard Deviations of Income by Educational Group and Decomposition of Inequality Within and Between Educational Groups and Persons

Panel A, means (2009 U.S. \$)

\begin{tabular}{lcccc}
\hline 1957-9 cohort & $1985-2005$ & $1985-1991$ & $1993-1999$ & $1999-2005$ \\
< High School & 19,766 & 18,409 & 19,755 & 23,186 \\
High School & 31,171 & 28,931 & 30,002 & 35,805 \\
Some College & 40,676 & 36,699 & 40,335 & 45,976 \\
College & 57,284 & 50,582 & 57,694 & 65,854 \\
1962-4 cohort & $1991-2009$ & $1991-1997$ & $1997-2003$ & $2003-2009$ \\
$<$ High School & 20,655 & 18,768 & 20,942 & 22,900 \\
High School & 30,780 & 27,640 & 31,950 & 34,238 \\
Some College & 41,051 & 36,428 & 41,523 & 47,074 \\
College & 61,731 & 55,768 & 62,681 & 68,284
\end{tabular}

Panel B, medians

\begin{tabular}{lcccc}
\hline 1957-9 cohort & $1985-2005$ & $1985-1991$ & $1993-1999$ & $1999-2005$ \\
$<$ High School & 16,949 & 15,498 & 15,991 & 17,341 \\
High School & 29,072 & 26,929 & 28,427 & 32,784 \\
Some College & 37,973 & 34,990 & 37,756 & 42,709 \\
College & 53,866 & 46,944 & 51,340 & 58,106 \\
1962-4 cohort & $1991-2009$ & $1991-1997$ & $1997-2003$ & $2003-2009$ \\
$<$ High School & 16,395 & 15,148 & 15,638 & 16,604 \\
High School & 28,225 & 25,105 & 28,682 & 31,040 \\
Some College & 37,601 & 33,908 & 37,904 & 42,100 \\
College & 59,051 & 52,332 & 58,814 & 63,430
\end{tabular}

Panel C, standard deviations

\begin{tabular}{|c|c|c|c|c|}
\hline 1957-9 cohort & 1985-2005 & 1985-1991 & 1993-1999 & 1999-2005 \\
\hline$<$ High School & 13,165 & 12,132 & 14,569 & 18,918 \\
\hline High School & 16,764 & 15,41 & 17,569 & 22,871 \\
\hline Some College & 20,633 & 18,787 & 23,287 & 27,977 \\
\hline College & 25,222 & 23,145 & 28,751 & 34,577 \\
\hline 1962-4 cohort & 1991-2009 & 1991-1997 & 1997-2003 & 2003-2009 \\
\hline$<$ High School & 15,997 & 14,235 & 18,297 & 20,092 \\
\hline High School & 18,737 & 17,385 & 21,187 & 23,649 \\
\hline Some College & 21,491 & 20,388 & 24,145 & 27,604 \\
\hline College & 26,050 & 23,556 & 30,065 & 33,519 \\
\hline \multicolumn{5}{|l|}{ Panel D, inequality decomposition } \\
\hline 1957-9 cohort & 1985-2005 & 1985-1991 & 1993-1999 & 1999-2005 \\
\hline Total & 0.254 & 0.214 & 0.240 & 0.274 \\
\hline Between Education & 0.044 & 0.043 & 0.046 & 0.046 \\
\hline Within Education, between persons & 0.122 & 0.129 & 0.154 & 0.177 \\
\hline Within persons & 0.087 & 0.042 & 0.040 & 0.051 \\
\hline 1962-4 cohort & 1991-2009 & 1991-1997 & 1997-2003 & 2003-2009 \\
\hline Total & 0.281 & 0.243 & 0.276 & 0.295 \\
\hline Between Education & 0.052 & 0.052 & 0.052 & 0.054 \\
\hline Within Education, between persons & 0.138 & 0.145 & 0.170 & 0.186 \\
\hline Within person & 0.092 & 0.046 & 0.054 & 0.055 \\
\hline
\end{tabular}



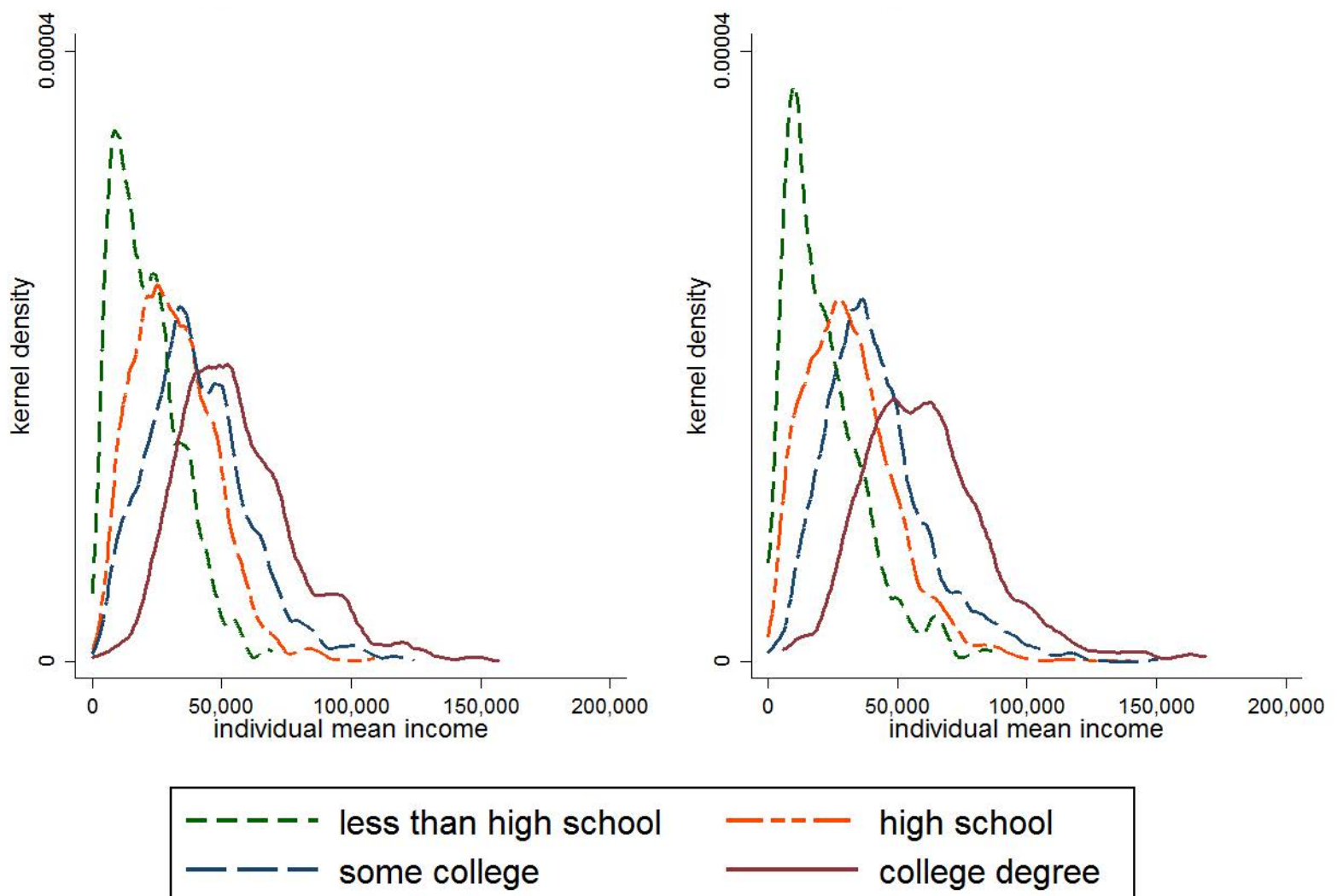

Figure 3: Densities of Income by Education

Figure 3 illustrates why education accounts for relatively little inequality. These kernel density plots show the distributions of respondents' mean income (averaged over the entire period of roughly 20 years) according to education. While it is immediately evident that the densities for higher educational categories lie further to the right, it is equally apparent that there is substantial overlap between categories. In the older cohort, for example, almost 23 percent of respondents in the college category have an average income less than the median for respondents in the high school category. In the younger cohort the figure is 13 percent, reflecting the impression in Figure 3 that the overlap in income is less among those born $1962-4$.

It might be objected that education explains only a small share of inequality because the educational groupings we are using are not sufficiently discriminating: the category "college" for example, puts together graduates from different colleges and from different majors and also includes people with post-graduate degrees. Perhaps if we had a finer categorization of education we could explain more; some of the within-education inequality would then become between-education inequality. We repeated our analyses with six categories of education: "less than high school" "GED" "high school diploma" "some college" "completed college" and "advanced degree (MA, PhD or professional qualification)" This had little impact on the share of inequality explained by education. For example, if we consider only the 
Table 5: Decomposition of Half the Squared Coefficient of Variation Within Educational Groups

\begin{tabular}{lcccc}
\hline & $<$ High School & High School & Some College & College \\
\hline 1957-9 cohort & & & & \\
$\quad$ Total & 0.364 & 0.213 & 0.194 & 0.150 \\
Between & 0.197 & 0.125 & 0.118 & 0.085 \\
Within & 0.167 & 0.088 & 0.077 & 0.064 \\
1962-4 cohort & & & & \\
$\quad$ Total & 0.459 & 0.261 & 0.204 & 0.144 \\
Between & 0.262 & 0.162 & 0.120 & 0.085 \\
Within & 0.197 & 0.099 & 0.084 & 0.058 \\
\hline
\end{tabular}

results for the entire period, the original four categories of education accounted for $0.044 /(0.044+0.122)=26.5$ percent of total adjusted (for within-person volatility) inequality in the older cohort and 27.4 percent in the younger cohort. Using the six categories these percentages change to 27 percent and 27.8 percent. The additional contributions from the use of the finer categorization to between-group inequality in each of the sub-periods are similarly very small.

Table 5 shows the decomposition of $h$ into within-person (volatility) and betweenperson components within each of our four original educational categories. Total inequality declines as we move to higher levels of education and so does adjusted inequality (that is, the between-person component). In fact, the two move almost in step because the ratio of within-person to total inequality is always (in each educational category and for both cohorts) between 55 and 60 percent. However, Table 5 shows clearly that not only is there less inequality in incomes at the top of the educational distribution but also that inequality among those who did not attend college was greater in the 1962-4 cohort than in the 1957-9 cohort.

\section{Counterfactuals}

In the final part of our analysis we simulate the consequences, for inequality, of changes in the educational distribution and in the returns to education. By changes in the educational distribution we mean changing the distribution of observations among the four educational categories in a way that might correspond to the consequences of possible policy changes that would affect educational attainment. By changes in the returns to education we mean changes in the incomes of people according to their level of education such that, for example, the gaps in average income between educational categories diminish. Together these simulations capture the mechanisms by which changes in education are generally expected to affect inequality: if more people acquire a college education, this will reduce the variation in educational attainment and the college premium (the degree to which college graduates earn more) should fall in response to the larger supply of college graduates. In the appendix we discuss the assumptions under which the results of these simulations might be considered to give us information about causal consequences. 
We simulate a shift in the educational distribution as follows. Write overall mean income in terms of the education groups' mean incomes as $\mu=\sum p_{j} \mu_{j}$ (recall that $j$ subscripts educational groups). Substituting this into Equation (5) we can rewrite $h$ as follows:

$$
\begin{aligned}
& h=h_{b e}+h_{b p}+h_{w}=\frac{1}{2\left(\sum_{j} p_{j} \mu_{j}\right)^{2}} \sum_{j} p_{j} \\
& {\left[\mu_{j}-\left(\sum_{j} p_{j} \mu_{j}\right)^{2}\right]+\left[\frac{1}{2 \mu^{2}} \sum_{j} p_{j} \sum_{i \mid j} p_{i \mid j}\left(\mu_{i \mid j}-\mu_{j}\right)^{2}\right]+\left[\frac{1}{2 \mu^{2}} \sum_{j} p_{j} \sum_{i \mid j} p_{i \mid j} \sigma_{i \mid j}^{2}\right] .}
\end{aligned}
$$

This makes it clear that $h$ depends on individual mean incomes, $\mu_{i \mid j}$, mean incomes in each educational group, $\mu_{j}$, individual within-person variation in income, $\sigma_{i \mid j}$, and the individual and group proportions $\left(p_{i \mid j}\right.$ and $p_{j}$ ) We now ask, if we were to change the education group proportions, keeping all the other parameters unchanged ${ }^{9}$ how much hypothetically, would income inequality change? From Equation (6) we see that this will affect all three components of inequality. In particular, by hypothetically moving people to the college category we will reduce betweenperson inequality.

The maximum degree to which inequality could be reduced in this way would result from moving all respondents into the college category. This would eliminate all between-education inequality and within-group inequality and thus total adjusted inequality would be 0.085 for both cohorts, as shown in the final column of Table 5. This would roughly halve inequality, from an adjusted $h$ of 0.167 for the older cohort and 0.189 for the younger. But not only does this assume no alteration in inequality within the college category, it also supposes a six-fold increase in the size of the category. We therefore consider in more detail two somewhat more plausible sets of changes. In the first case we simulate the consequences of a general upward shift in educational attainment, such that $k$ percent of people are moved from each education level to the next highest. This is equivalent to moving $k$ percent of people from the lowest category (less than high school) to the highest (college). We vary $k$ from one percent to 10 percent. In the second set of simulations we shift people from the high school category to the some college category. We might think of this as the consequence of a policy, or other intervention, that increases the rate of transition from high school to college, though it does not affect the share of the population with a four-year college degree or higher qualification. We interpret these simulations as telling us what inequality in theNLSY79 data would have been if the world had been as it is in the particular simulation rather than as it really was. The results of these and of our later simulations (where we change incomes) are almost exactly the same for both of the birth cohorts on which we focus and so we present the results only for the 1962-4 cohort. ${ }^{10}$

In our first simulation, an upward shift of one percent in the educational distribution reduces total inequality from 0.281 to 0.279 and reduces adjusted inequality (omitting the within-person component) from 0.19 to 0.188 . A 10 percent increase reduces total inequality to 0.253 and adjusted inequality to 0.171 (this result is shown in line 1 of panel B of Table 6, to be discussed later). The relationship between the percentage increase and the percentage reduction in inequality is linear: a one 
percent increase reduces adjusted inequality by about one percent. In the second simulation, an upward shift of 10 percent from high school to some college reduces adjusted inequality by four percent (from 0.19 to 0.182 ; see line 1 of panel C of Table 6). This relationship is also linear: moving one percent of those who ended their education when they graduated high school to the some college category reduces adjusted inequality by 0.4 percent. As we might have expected, moving people from the lowest to the highest educational categories has a larger impact than moving them from the second lowest to the second highest category. Overall, however, the effect of changing the educational distribution is very modest. Inequality is not very sensitive to upward shifts in the educational distribution.

In making these simulations and deriving the hypothetical inequality, however, we kept the incomes of individuals unchanged. Yet the main mechanism by which increasing the share of the population with a college degree is expected to reduce inequality is because it will change the balance of the supply of, and demand for, college graduates (Autor 2014; Goldin and Katz 2008). So we now simulate what inequality might have been in our data had the average incomes of people in the different educational categories been more similar. To do this, we adjust the incomes of people in the $j^{\text {th }}$ educational category by the multiplicative factor $\delta_{j}$. We can define the adjusted means for each educational category and overall, and the adjusted within-person variance, as

$$
\begin{aligned}
\mu_{j}^{*} & =\sum_{j} p_{i \mid j} \delta_{j} \mu_{i \mid j} \\
\mu^{*} & =\sum_{j} p_{j} \mu_{j}^{*} \\
\sigma_{i \mid j}^{* 2} & =\delta_{j}^{2} \sigma_{i \mid j}^{2} .
\end{aligned}
$$

We then insert these quantities in the formula for $h$ to yield the hypothetical inequality and its component parts:

$$
\begin{aligned}
& h=h_{b e}+h_{b p}+h_{w}=\left[\frac{1}{2 \mu^{* 2}} \sum_{j} p_{j}\left(\mu_{j}^{*}-\mu^{*}\right)^{2}\right] \\
& +\left[\frac{1}{2 \mu^{* 2}} \sum_{j} p_{j} \sum_{i \mid j} p_{i \mid j}\left(\delta_{j} \mu_{i \mid j}-\mu_{j}^{*}\right)^{2}\right]+\left[\frac{1}{2 \mu^{* 2}} \sum_{j} p_{j} \sum_{i \mid j} p_{i \mid j} \delta_{j}^{2} \sigma_{i \mid j}^{2}\right]
\end{aligned}
$$

The simulations we consider reduce the incomes of those in the college and some college categories in our data ( $\delta_{j}$ in these cases will be less than one) and so reduce both the mean and variance of incomes in these categories. In our simulations we do not change the earnings of those in the less than high school and high school groups (for them, $\delta_{j}=1$ ). We pick values of $\delta_{j}$ for the college and some college groups so that the gap in average incomes between them and the high school group is hypothetically reduced by half, by a quarter, and by 10 percent. Between 1979 and 2012 the gap in median earnings between those with a four-year college degree and those with only a high school education increased from $\$ 30,000$ to $\$ 58,000$, or by 93 percent (Autor 2014 844, Figure 1). If household income gaps had increased by the same proportion then reducing them by one half would return us to the differences that prevailed in 1979. 
Panel A of Table 6 shows the results of reducing the income gap by 10, 25 and 50 percent, and panels $B$ and $C$ show the combined impact of changing the income gap and changing the distribution of educational attainment. The effects of changing only the income gap are quite modest: a decline of 50 percent reduces inequality by about 16 percent (from an adjusted $h$ value of 0.190 to 0.159 ). ${ }^{11}$ A decline of 10 percent reduces adjusted inequality from 0.19 to 0.183 , a little less than four percent. A reduction in the income gap might be brought about by an increase in the supply of college-educated workers, and the first line of panel B shows the effect of moving 10 percent of people from the lowest to the highest educational category; as noted earlier this reduces inequality by 10 percent. A simultaneous narrowing of the income gap brings about larger reductions, though the effects of the change in the educational distribution and the reduction of the income gap are additive. The consequence of a 10 percent reduction in the income gap combined with a 10 percent shift from less than high school to college, for example, is a decline of 13.57 percent, almost exactly equal to the sum of the effects of a 10 percent reduction in the gap ( 3.65 percent) and a 10 percent shift in the distribution (9.94 percent). The combined effect of reductions in the income gap and shifts from the high school to the some college category are also additive, though less exactly so. This being the case, the largest reduction in inequality occurs when we hypothetically move people from the lowest to the highest educational categories and reduce the income gaps by half. As we should have expected, reducing the income gap has a large effect on the inequality between educational categories: a 50 percent reduction in the gap reduces between-education inequality by 62 percent. But because inequality between educational groups is only a small part of total inequality, the impact on total inequality is quite modest.

\section{Conclusions}

We have addressed two issues in this article. The first, and less important, was to provide estimates of income inequality for members of the NLSY79 cohorts purged of the effects of income volatility. The second was to use these corrected estimates to investigate the degree to which education can account for inequality and to carry out some simulations of the possible effects on inequality of changing the distribution of, and returns to education. We found that only about 20 percent of income inequality can be explained by a measure that distinguishes four categories of education (a four-year college degree and higher, some college but less than a four-year degree, completed high school or GED, and less than high school). In our simulations we found that neither an upward shift in the educational distribution nor a reduction in the average gap in income between those with and those without a college education had a substantial impact on inequality.

Moving to a finer categorization of education added very little to its explanatory power. Adding other demographic characteristics has similarly little consequence. In further analyses we replaced the four educational categories with 36 categories defined by the combination of six educational categories, gender, and three races (white, black, other). As we saw earlier, the six educational categories alone account for 27 percent and 27.8 percent of total (adjusted) inequality over the whole period 
Table 6: Simulated Inequality Reducing the Income Gap by 10, 25 and 50 percent

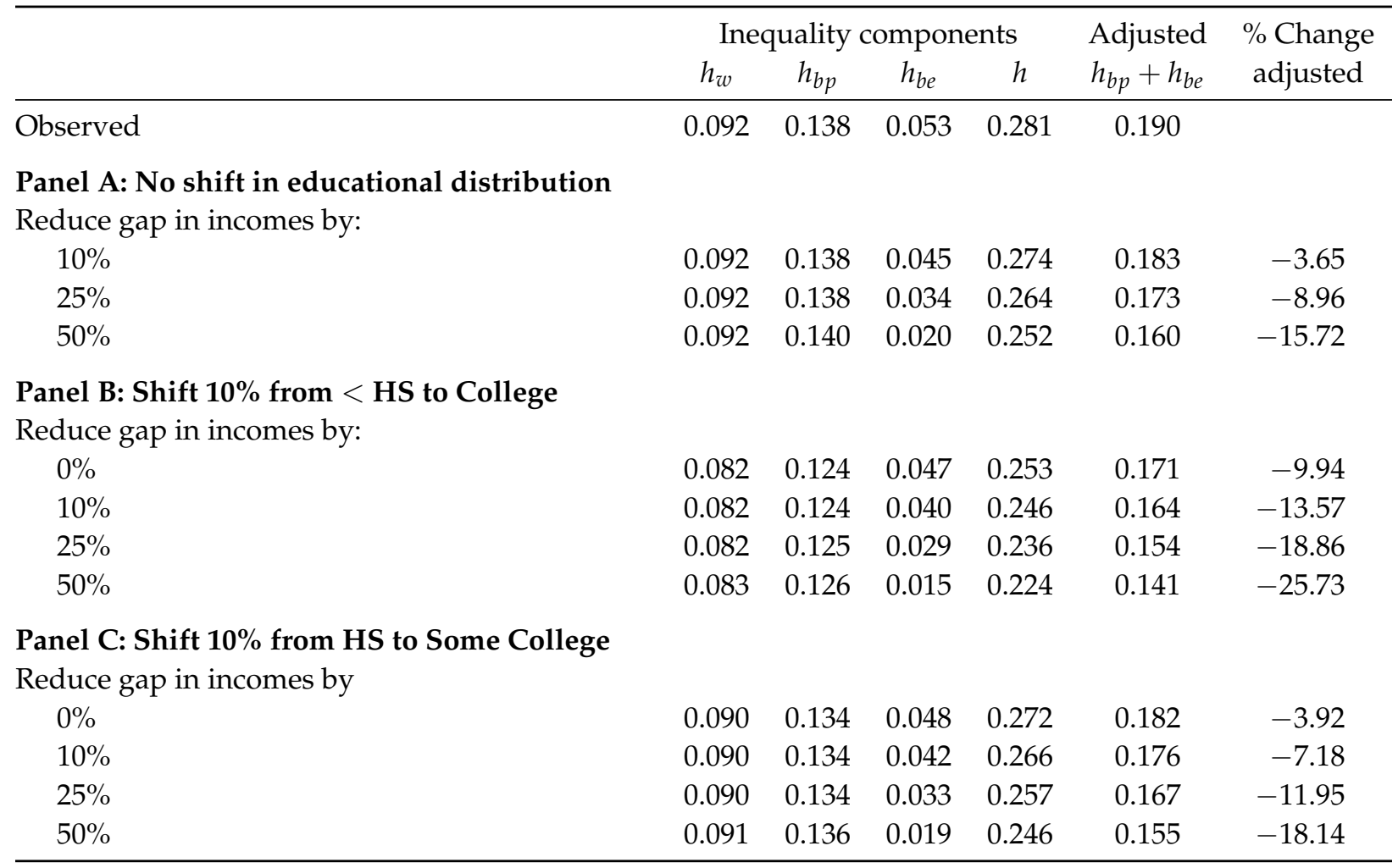

Note: Adjusted inequality is total inequality minus within-person inequality.

in the two birth cohorts (compared with 26.5 percent and 27.4 percent when we use four categories). Using all 36 combinations of education, sex and race this increases to 34.5 percent and 33.2 percent.

For reasons already explained, our analysis has been concerned with household income, in contrast to much work by economists that relates individual earnings to education. We get essentially identical results to those reported here if we replace income with individual earnings. We constructed our earnings measure using three NLSY79 questions: total income from military, total income from farm or business, and total income from wage or salary in the previous year. We then conducted two decompositions of earnings, the results of which, together with the decomposition of household income, are shown in Table 7. In the "earnings1" analysis, we used an earnings observation only when it had a matched income observation that we used in our initial income analyses. In the "earnings2" analysis, we used all available earnings observations. What is most striking in Table 7 is that, although inequality in earnings is greater than inequality in income-in some cases substantially so-between-education inequality is less for earnings than for income. The greater inequality in earnings is driven by more inequality among people within educational categories. The pooling of earnings and other sources of income that make up household income ameliorates inequality, especially among people with the same level of education. But the similarity of our results using 
Table 7: Decompositions of Inequality Using Income and Two Measures of Earnings

\begin{tabular}{lccc}
\hline & Income & Earning1 & Earning2 \\
\hline $\mathbf{1 9 5 7 - 9}$ cohort & $1985-2005$ & $1985-2005$ & $1985-2005$ \\
Total & 0.254 & 0.295 & 0.331 \\
Between Education & 0.044 & 0.034 & 0.039 \\
Within Education, between persons & 0.122 & 0.171 & 0.185 \\
Within persons & 0.087 & 0.090 & 0.107 \\
$\mathbf{1 9 6 2 - 4}$ cohort & $1991-2009$ & $1991-2009$ & $1991-2009$ \\
Total & 0.281 & 0.313 & 0.343 \\
Between Education & 0.052 & 0.042 & 0.046 \\
Within Education, between persons & 0.138 & 0.177 & 0.191 \\
Within persons & 0.092 & 0.093 & 0.106 \\
\hline
\end{tabular}

household income and individual earnings demonstrates that our findings based on the former are not driven by the inclusion of transfer incomes such as AFDC, food stamps and unemployment compensation.

As we noted earlier, the results of our simulations should be interpreted as hypothetical outcomes for the NLSY79 cohort had the world been different. This leaves open the question of whether our simulations are informative about the possible consequences of policy-driven, or other, changes to US education. In fact, there seem to be good reasons to think that our findings for the NLSY79 cohort probably overstate the extent to which education could ameliorate overall inequality. For one thing, by focusing on specific birth cohorts we have excluded one very important dimension of inequality, namely age and factors correlated with age such as career stage. This means that we observe less inequality in our data than we would find had we analyzed the entire population or the working-age population. Education probably explains more of inequality in our data, and inequality is more sensitive to it, than in the general population. For another thing, even if we could immediately and substantially increase the share of the current year's high school graduates who will attend and graduate from a four-year college, this would have little impact on the educational distribution of the entire working-age population or on their incomes. It would take many years before such educational changes percolated through a large share of the population. ${ }^{12}$

In our simulations that changed the distribution of education we assumed that moving individuals who would otherwise have obtained a lower level of education to a higher level would leave the mean and standard deviation of income unchanged in both their origin and destination educational categories. It might, however, be more reasonable to think that such a change would reduce the mean in both cases. The origin mean would likely decline because those people who would respond to new incentives or policies to acquire more education would be positively selected, in the sense that they would have more favorable observed and unobserved characteristics that would lead them to have higher incomes. But because their characteristics are unlikely to be as favorable as those of people who would, in any case, have acquired a higher level of education, their movement into 
that level will likely reduce mean income in the destination category. By the same arguments, the shift in persons would probably reduce the standard deviation of incomes in the origin (because of the loss of persons from the upper part of the within-origin distribution of income) and increase it in the destination (because of a growth in the share of persons in the lower part of the within-destination distribution of income). These changes would have offsetting effects. Reducing the mean in the origin and increasing the standard deviation in the destination will exacerbate inequality; reducing the standard deviation in the origin and reducing the mean in the destination will ameliorate it. We believe that, by virtue of these offsetting effects, our naïve estimates, which assumed none of these changes operated, are unlikely to be wildly inaccurate. Furthermore, each of these changes is likely to have quite small consequences for inequality. Evidence for this comes from our second set of simulations, which showed that reducing both the mean and the standard deviation of income among the college-educated categories had rather modest effects, despite the fact that these changes should both reduce inequality.

In his review of the development literature, $\operatorname{Ram}(1989,193)$ concluded that in developing countries, "Notwithstanding the obvious faith many people share regarding the potential of educational expansion as a powerful equalizer, neither any defensible theoretical framework nor the weight of available evidence seems to justify such faith on scientific grounds." The same could be said of the United States. While there are many good reasons for wanting to expand education, among which are the likelihood that doing so would increase equality of opportunity and would lead to a more skilled workforce, a healthier population and a better informed citizenry, reducing inequality is not one of them. The growth in inequality in the United States has been driven substantially by the widening gap between the very top of the distribution and the rest (something our analysis has not spoken to). Even outside the top few percentiles of the distribution, education accounts for only a modest share of inequality and any feasible changes in education are unlikely to do much to ameliorate income inequality in the United States even in the long term.

\section{Notes}

1 According to our calculations, between one third and one half of the growth in inequality in disposable household income in the United States between 1979 and 2007 was due to the increasing share of income accruing to households in the top one percent of the income distribution. Our analyses and discussion do not speak to this phenomenon.

2 The relationship between education and income inequality has been widely studied by economists, particularly development economists. Their analyses have usually taken the form of cross-country regressions, regressing a measure of inequality, such as the Gini coefficient, on aggregate measures of educational attainment and educational inequality. Although many of these studies have found a positive relationship between educational inequality and income inequality (for example Park 1996 and Gregorio and Lee 2002) the magnitude of the effect of education is often quite small (see the estimates in Checchi 2004, for example).

3 We also conducted the same analyses using a cross-sectional sample and the results are very similar. 
4 We refer to "NLSY79 respondents' household incomes" but this should be understood as a less cumbersome way of writing "the incomes of the households in which NLSY79 respondents resided"

5 The NLS homepage provides detailed information on income and other variables we use in this article. See: http://www.bls.gov/nls/nlsy79.htm.

6 Our results are not sensitive to our imputations: we find almost identical inequality and partitions of inequality into its components using data without any imputation.

7 This approach is standard in the literature: see, for example, Gottschalk and Moffitt (1994).

8 The figures in panels A, B and C of Table 4 are derived by assigning to each NLSY79 respondent his or her average income in the time period shown in the columns of the table and then computing means, medians and standard deviations from these withinperson averages.

9 We can do this without changing the individual proportions because they are expressed as probabilities conditional on group membership (that is, the $p_{i \mid j}$ in Equation (6) are conditional probabilities).

10 The complete results of all simulations are available from the authors on request.

11 It reduces the gap in the observed $h$ by less (around 10 percent, from 0.28 to 0.25 ) because the adjustments we make have no impact on within-person inequality.

12 There are other reasons to think that educational upgrading may not reduce inequality. In a recent paper, Beaudry, Green and Sand (2013) show that the demand for skills in the United States, which had been increasing during the closing decades of the twentieth century, began to decline around the year 2000. One consequence has been that "highskilled workers have moved down the occupational ladder and have begun to perform jobs traditionally performed by lower-skilled workers. This de-skilling process, in turn, results in high-skilled workers pushing low-skilled workers even further down the occupational ladder and, to some degree, out of the labor force all together" (Beaudry, Green, and Sand 2013, 2).

\section{References}

Altonji, Joseph G., Prashant Bharadwaji and Fabian Lange. 2012. "Changes in the Characteristics of American Youth: Implications for Adult Outcomes." Journal of Labor Economics 30(4):783-828. http://dx.doi.org/10.1086/666536.

Auten, Gerald, Geoffrey Gee, and Nicholas Turner. 2013. "Income Inequality, Mobility, and Turnover at the top of the US, 1987-2010." American Economic Review 103(3):168-72. http://dx.doi.org/10.1257/aer.103.3.168.

Autor, David. 2014. "Skills, Education, and the Rise of Earnings Inequality among the 'Other 99 Percent."' Science 344(6186):843-51. http://dx . doi .org/10.1126/science. 1251868.

Beaudry, Paul, David A. Green and Bejamin M. Sand. 2013. “The Great Reversal in the Demand for Skill and Cognitive Tasks." Working Paper No. 18901, National Bureau of Economic Research.

Bound, John and Alan B. Krueger. 1991. "The Extent of Measurement Error in Longitudinal Earnings Data: Do Two Wrong Make a Right?" Journal of Labor Economics 9(1):1-24. http://dx.doi.org/10.1086/298256.

Bourguignon, Francois. 1979. “Decomposable Income Inequality Measures.” Econometrica 47(4):901-20. http://dx.doi.org/10.2307/1914138. 
Bradbury, Katharine. 2011. "Trends in U.S. Family Income Mobility, 1969-2006." Working Papers No. 11-10. Federal Reserve Bank of Boston.

Bradbury, Katharine and Jane Katz. 2002. "Are lifetime incomes growing more unequal? Looking at new evidence on family income mobility." Regional Review 12(4):2-5.

Breen Richard and Leire Salazar. 2011. "Educational Assortative Mating and Earnings Inequality in the United States." American Journal of Sociology 117(3):808-43. http: //dx.doi.org/10.1086/661778.

Buchinsky, Moshe and Jennifer Hunt. 1999. "Wage Mobility in the United States." The Review of Economics and Statistics 81(3):351-68. http://dx. doi .org/10.1162/003465399558210.

Carroll, Robert. 2010. “Income Mobility and the Persistence of Millionaire, 1999 to 2007." Special Report No. 180 Tax Foundation.

Checchi, Daniele. 2004. "Does educational achievement help to explain income inequality?" Pp. 81-111 in Inequality, Growth and Poverty in an Era of Liberalization and Globalization, edited by Cornia, Giovanni A. New York: Oxford University Press. http://dx.doi .org/ 10.1093/0199271410.003.0004.

Congressional Budget Office (CBO). 2011. Trends in the Distribution of Household Income Between 1979 and 2007. Washington, DC: The Congress of the United States Congressional Budget Office.

Cowell Frank and Stephen Jenkins. 1995. "How Much Inequality Can we Explain? A Methodology and an Application to the United States." Economic Journal 105(429):421-30. http://dx.doi.org/10.2307/2235501.

DiNardo, Fortin and Thomas Lemieux. 1996. "Labor Market Institution and the Distribution of Wages, 1973-1992: A Semiparametric Approach." Econometrica 64(5):1001-44. http: //dx.doi.org/10.2307/2171954.

Gangl, Markus. 2005. "Income Inequality, Permanent Income and Income Dynamics: Comparing Europe to the United States." Work and Occupations 32(2):140-62. http://dx.doi.org/10.1177/0730888404274354.

Ganzeboom, Harry, Donald Treiman, and Wout Ultee. 1991. “Comparative Intergenerational Stratification Research: Three Generations and Beyond." Annual Review of Sociology 17:277-302. http://dx.doi.org/10.1146/annurev.so.17.080191.001425.

Goldin Claudia and Lawrence Katz. 2008. The Race between Education and Technology. Cambridge, MA: Belknap Press.

Gottschalk, Peter. 1997. "Inequality, Income Growth, and Mobility: The Basic Facts." Journal of Economic Perspectives 11(2):21-40. http://dx . doi .org/10.1257/jep.11.2.21.

Gottschalk, Peter and Robert Moffitt. 1994. "The Growth of Earnings Instability in the U.S. Labor Market." Brookings Papers on Economic Activity 2:217-272. http://dx.doi .org/10 . $2307 / 2534657$.

Gottschalk, Peter and Timothy M. Smeeding. 1997. "Cross-National Comparisons of Earnings in Income Inequality." Journal of Economic Literature 35(2):633-687.

Gregorio, Jose and Jong-Wha Lee. 2003. "Education and Income Inequality: New Evidence from Cross-Country Data." Review of Income and Wealth 48(3):395-416. http: //dx . doi . org/10.1111/1475-4991.00060.

Hallinan, M. T. 1988. "Equality of Educational Opportunity." Annual Review of Sociology 14:249-68. http://dx.doi.org/10.1146/annurev.so.14.080188.001341.

Hout, Michael. 2004. "How Inequality May Affect Intergenerational Mobility, Social Inequality" Pp. 969-87 in Social Inequality, edited by Neckerman, Kathryn M.. New York: Russell Sage Foundation. 
Hubbard, R. G, J. Numms and W. Randolph. 1992. "Household Income Changes over Time: Some Basic Questions and Facts" Tax Notes August 24, 1992.

Jencks, Christopher, Marshall Smith, Henry Acland, Mary Jo Bane, David Cohen, Herbert Gintis, Barbara Heyns, and Stephan Michelson. 1972. Inequality: A Reassessment of the Effect of Family and Schooling in America New York: Basic Books.

Jencks, Christopher, Susan Bartlett, Mary Corcoran, James Crouse, David Eaglesfield, Gregory Jackson, Kent McClelland, Peter Mueser, Michael Olneck, Joseph Schwartz, Sherry Ward, and Jill Williams. 1979. Who Gets Ahead? The Determinants of Economic Success in America New York: Basic Books.

Kim, Changhwan and Arthur Sakamoto. 2008. "The Rise of Intra-Occupational Wage Inequality in the United States, 1983-2002." American Sociological Review 73(1):129-57. http://dx.doi.org/10.1177/000312240807300107.

Krugman, Paul. 1992. "The Rich, the Right, and the Facts: Deconstructing the Income Distribution Debate." The American Prospect Fall, 19-31.

Krugman, Paul. 2015. “Knowledge Isn't Power." New York Times, October 23, 2015. http: //www.nytimes.com/2015/02/23/opinion/paul-krugman-knowledge-isnt-power. html?.

Levine, Linda. 2012. The U.S. Income Distribution and Mobility: Trends and International Comparisons Washington: Congressional Research Service.

McCall, Leslie and Lane Kenworthy. 2009. "Americans' Social Policy Preferences in the Era of Rising Inequality." Perspectives on Politics 7(3):459-84. http://dx . doi .org/10.1017/ S1537592709990818.

McCall, Leslie and Christine Percheski. 2010. “Income Inequality: New Trends and Research Directions." Annual Review of Sociology 36:329-47. http://dx.doi .org/10.1146/ annurev.soc.012809.102541.

McMurrer, Daniel P. and Isabel V. Sawhill. 1996. "Economic Mobility in the United States." Opportunity in America Series, companion piece to No. 3, Urban Institute.

Mookherjee, Dilip and Anthony Shorrocks. 1982. "A Decomposition Analysis of the Trend in UK Income Inequality." The Economic Journal 92(368):886-902. http://dx . doi .org/10. 1146/annurev.soc.012809.102541.

Park, Kang. 1996. "Educational expansion and educational inequality on income distribution." Economics of Education Review 15(1):51-8. http://dx.doi.org/10.1016/ 0272-7757 (95) 00000-3.

Ram, Rati. 1989. “Can Educational Expansion Reduce Income Inequality in Less-Developed Countries?" Economics of Education Review 8(2):185-9. http://dx.doi.org/10.1016/ 0272-7757 (89) 90006-X.

Rosenfeld, Rachel A. 1992. "Job Mobility and Career Processes." Annual Review of Sociology 18:39-61. http://dx.doi.org/10.1146/annurev.so.18.080192.000351.

Sawhill, Isabel V. and Mark Condon. 1992. "Income Mobility and Permanent Income Inequality" Research Paper No. 6723, Urban Institute.

Shorrocks, Anthony. 1980. "Class of Additively Decomposable Inequality Measures." Econometrica 48(3):613-25. http: //dx. doi .org/10.2307/1913126.

Thurow, Lester. 1975. Generating Inequality New York: Basic Books.

Van Kerm, Philippe. 2004. “What Lies Behind Income Mobility? Re-ranking and Distributional Change in Belgium, Western Germany, and the USA." Economica 71(282):223-239. http://dx.doi.org/10.1111/j.0013-0427.2004.00367.x. 
Western, Bruce, Deirdre Bloome, and Christine Percheski. 2008. "Inequality among American Families with Children, 1975 to 2005." American Sociological Review 73(6):903-920. http: //dx.doi.org/10.1177/000312240807300602.

Richard Breen: Nuffield College and Department of Sociology, University of Oxford. E-mail: richard.breen@nuffield.ox.ac.uk.

Inkwan Chung: Department of Sociology, Yale University. E-mail: inkwan.chung@yale.edu. 